This is an electronic version of an article published in Gallagher, K. (2006). Sexual

fundamentalism and performances of masculinity: An ethnographic scene study.

International Journal of Gay and Lesbian Issues in Education, 4(1), 47-76. Cognition and

Instruction is available online at: www.tandfonline.com with

http://www.tandfonline.com/openurl?genre=article\&issn=1541-

$0889 \&$ volume $=4 \&$ issue $=1 \&$ spage $=47$

\title{
Sexual Fundamentalism and Performances of Masculinty: An Ethnographic Scene Study
}

\begin{abstract}
:
The study, on which this paper is based, is titled, Drama Education, Youth, and Social Cohesion: (re)constructing identities in urban contexts. It has examined the experiences of youth in urban drama classrooms in order to develop a theoretical and empirically grounded account of the dynamic social forces of inclusion and exclusion experienced by youth in their unique contexts of North American schooling. The paper uses the form of theatre, itself: the ethnographic scenes organized into four "beats" at the outset of the paper are meant to theatrically render the cultural performances of youth and researchers in the context of a diverse urban drama classroom. In this classroom, students, teacher and researchers are engaged in a lively and often disturbing debate about sexuality in particular, and gay/lesbian issues more generally. Questions about the ways in which sexuality and other identity markers are socially constructed and performed, how the moral, gendered and discoursed cultures created in classrooms reinscribe historical inequities are central to both the ethnographic scenes presented and the epilogue which follows. The play itself is drawn from fieldnotes, researcher reflections, and interview transcripts. Aspects of youth culture, performance (cultural and artistic), the construction of identities- particularly in relation to theories of masculinity and the (heterosexual) "pass"- are subsequently deconstructed in the epilogue.
\end{abstract}




\title{
Sexual Fundamentalism and Performances of Masculinity: An Ethnographic Scene Study
}

Dr. Kathleen Gallagher

Associate Professor

Ontario Institute for Studies in Education of the University of Toronto

Department of Curriculum, Teaching and Learning

252 Bloor Street West

Toronto, Ontario M5S 1V6

Telephone: 416 923-6641 ext. 2015

Fax: 416 926-4744

Email: kgallagher@oise.utoronto.ca

\begin{abstract}
:
The study, on which this paper is based, is titled, Drama Education, Youth, and Social Cohesion: (re)constructing identities in urban contexts. It has examined the experiences of youth in urban drama classrooms in order to develop a theoretical and empirically grounded account of the dynamic social forces of inclusion and exclusion experienced by youth in their unique contexts of North American schooling. The paper uses the form of theatre, itself: the ethnographic scenes organized into four "beats" at the outset of the paper are meant to theatrically render the cultural performances of youth and researchers in the context of a diverse urban drama classroom. In this classroom students, teacher, and researchers are engaged in a lively and often disturbing debate about sexuality in particular, and gay/lesbian issues more generally. Questions about the ways in which sexuality and other identity markers are socially constructed and performed, how the moral, gendered and discoursed cultures created in classrooms reinscribe historical inequities are central to both the ethnographic scenes presented and the epilogue which follows. The play itself is drawn from fieldnotes, researcher reflections, and interview transcripts. Aspects of youth culture, performance (cultural and artistic), the construction of identities- particularly in relation to theories of masculinity and the (heterosexual) "pass"- are subsequently deconstructed in the epilogue.

Kathleen Gallagher (Ph.D) wishes to acknowledge the Social Sciences and Humanities Research Council of Canada for their generous support of this research. Dr. Gallagher holds a Canada Research Chair in Urban School Research in Pedagogy and Policy at the Ontario Institute for Studies in Education of the University of Toronto. Her book, Drama Education in the Lives of Girls: Imagining Possibilities (2000) won the American Education Research Association's distinguished book award for contribution to Curriculum Studies. Her recent book is an edited collection titled How Theatre Educates: Convergences and Counterpoints with Artists, Scholars, and Advocates (2003). Both are published by University of Toronto Press.
\end{abstract}




\section{Sexual Fundamentalism and Performances of Masculinty: An Ethnographic Scene Study}

\section{Prologue}

The Players ${ }^{1}$ :

Arden: White male, late twenties, research assistant

Philip: White male, late thirties, research assistant

Dominique: Black female, late twenties, research assistant

Kathleen: White female, late thirties, researcher

The scene begins in a Blackout. EMINEM's “Criminal” from the Marshall Mather's LP plays loudly.

My words are like a dagger with a jagged edge And they'll stab you in the head whether you're a fag or a lez

Homo sex, hermaph or transvez

Pansy dress

Hate fags? The answer's yes.

Homophobic? Nah you're just heterophobic

Staring at my jeans watching my genitals bulging

That's my mother-fucking balls

You better let go of them

They belong in my scrotum, you'll never get hold of em'

Hey it's me, Versace

(Whoops somebody shot me)

And I was just checking the male, get it, checking the male

How many records are you expecting to sell

After you're second LP sends you directly to jail?

C'mon relax guy, I like gay men

Right, Ken?

Give me an Amen...

As the rap fades, the following male voice-over is heard ${ }^{2}$ :

A reported 2.5 million Canadians over the age of 18 will experience a depressive disorder and many of these problems commence during adolescence (Canadian Mental Health Association, 2002). One in five young Americans (children and adolescents) suffer from mental health problems (American Psychiatric Association, 2000). It is reported that 36\% of American 13-year olds felt "low" and 23\% of Canadian youth felt "low" at least once a week. A random community survey of 750 men between the ages of 18-27, conducted by researchers at York University in Toronto, Canada, found that $62.5 \%$ of the young men who reported attempting suicide at some time in their lives were

\footnotetext{
${ }^{1}$ The SSHRC-funded study from which these ethnographic scenes come is titled, Drama Education, Youth

${ }^{2}$ While all references appear in the printed text, they should not be read aloud in the performed text.
} 
gay or bisexual (Bagley and Tremblay, 1997) Many have studied the connection between school stress and emotional health (see Ma, 2000; Torsheim \& Wold, 2001) and evidence is mounting to suggest that experiencing anti-gay/lesbian violence during adolescence is related to long-term stress and anxiety (Rivers, 1997, cited in Schneider 1997). And yet schools, in most western countries, are seen as the primary instrument for improving the lives of children and youth.

Music resumes then fades slowly to silence.

\section{BEAT ONE}

Kathleen: (appearing upstage right, speaking) Beat One: "The Dumbshow"

Lights up on "The Dumbshow."

Two spotlights fixed on two couples dancing, slowly, awkwardly, grade-seven-like. Centre stage: Dominique and Phil, Kathleen and Arden. Bright spot and silence while they dance.

Fade to Black

Two spotlights up on two couples dancing, slowly, awkwardly, grade-seven-like. Centre stage: Dominique and Kathleen, Arden and Phil. Silence.

Lights dim on Kathleen and Dominique. They freeze. Arden steps forward as lights come up downstage left. Phil moves toward downstage right and reveals a sign, which reads:

\section{"Our fears are the sources of silences, and men's silence is what keeps the system running"}

Michael Kimmel, Masculinity as Homophobia: Fear, shame and silence in the construction of gender identity, 1994.

Arden: Looking back on December 11, 2002. I was silent. That still sits heavily on my shoulders. For all the reasons that made perfect sense at the time - not wanting to make the discussion about me, wanting to give the students a chance to refute the hatred of their peers, not wanting to "compromise" the research, not wanting to take on the burden of being the sole gay voice in the room, wanting to let the conversation play out the way it might have if I wasn't there, even simply not wanting to submit myself to the even greater emotional bashing that would have been the case if I did speak - I still sit uneasily with that silence. I still sit uneasily, wondering if perhaps while the research wasn't compromised, perhaps I was. Because I know that when similar situations in the past have occurred, I have not been silent, because in every other role - as friend, teacher, artist, activist - I feel completely confident speaking. The choice I made to say nothing does not feel like I was being true to myself - and yet at the very same time is strangely validating of my authenticity, my integrity. I know that I couldn't speak because I couldn't lie - I couldn't say "I have friends..." or "I've heard..." or any other slippery 
elusive statement that wasn't solidly grounded in my own personal experience and reality. I couldn't speak without outing myself, because anything less would have felt dishonest. Since I thought outing myself would have drastically changed not only that discussion, but also any future research we would pursue in that context, I chose to say nothing at all. And I realize that doesn't feel like it was the wrong decision, at the time, in that place, in this specific classroom.

The other piece that feels important to write is how very much a few moments that day meant to me: Phil coming to sit beside me during the discussion, and asking me how I was as soon as it was just the five of us; Kathleen bringing me a glass of wine that afternoon to make the writing of this monologue easier; Dom calling me that evening to see how I was doing. I knew how much self-care each of them had to do that day, and so it amazed me that in the midst of that, they were nevertheless ready to unhesitatingly offer support and caring. That kindness was the best balm I could have asked for to treat the emotional wounds of that day.

I'm left with a question Phil asked in his reflection - "I cannot help but wonder how [Arden] will be able to steel himself for the challenge of returning to this classroom to conduct research." The answer is two-fold - I'm honestly not sure how, and if, I can, but I do know that writing this monologue has helped, indeed significantly so.

\section{BEAT TWO}

Kathleen: (upstage left, speaking) Beat Two: Field Notes or The "real life" drama of classroom "discussions"

(Classroom setting. Middleview Technical School. Grade 11 Drama classroom. Colorful walls bedecked with notices of upcoming plays around town and career posters. It is Friday, December 6, 2002. All students, teacher, and four researchers sit in a circle. The three student researchers take out pads of paper. Kathleen places a laptop on her lap while sitting on the floor. In the following scene, Phil speaks aloud-in direct address to the audience-all researcher notes that appear emboldened and in parentheses, as the scene unfolds. As participant-observer, he is both in the dialogue/scene and "observing"as researcher-from outside the discussion)

The Players ${ }^{3}$ :

Ms. Sarrow: Teacher White female, Canadian-born, Jewish

Dom: Black female, first-generation Canadian, Trinidadian decent, Research Assistant

Phil: White male, American-born, Research Assistant

Arden: White male, first-generation Canadian, Polish decent, Research Assistant

$K G$ : White female, first generation Canadian, Scottish decent, Researcher

Dion: Jamaican-born, Black male

Shahbib: Iraqui-born Brown male

Perry: Canadian-born, White male of Estonian decent

Natalie: Carribean-born, Black female

\footnotetext{
${ }^{3}$ To provide anonymity, all names of student and teacher participants and places in the research study are pseudonyms.
} 
Janus: White male, first- generation Canadian, Greek decent

Craig: White male, first- generation Canadian, Spanish and Scottish decent

J.P: White male, ethnicity unknown

Santos: White male, first-generation Canadian, Portuguese decent

Lenna: White female, first-generation Canadian, Portuguese decent

Rosaria: White female, first-generation Canadian, Italian decent

Neela: Black female, Ethiopian-born

Brent: White male, Canadian-born, ethnicity unknown

Viviana: White female, first-generation Canadian, Portuguese decent

Paula: Black female, Canadian-born

Ms. Sarrow: What did everybody think about the show yesterday?

Dion: $\quad$ Was one of the actors gay? (Wasn't able to hear the particulars, but he mentions that one of the actors seemed to be sitting on his chair in an effeminate way.)

\section{[General discussion of homosexuality]}

Dion: It's screwed up in the head to be gay.

Shahbib: $\quad$ Look at all the pretty girls in the world, and you're going to fall in love with someone named Bill?

\section{[Too much cross talk, hard to make out what anyone is saying.]}

Perry: With all the stuff that's happening in the world, why do people care about gays so much?

Natalie: $\quad$ Gays carry disease. That's why people care.

Ms. Sarrow: Natalie, is that what you got from the show, that gays carry disease? Before we go on with this discussion, I am going to ask you to think before you speak. If what you are saying is homophobic or full of hate, I am going to ask you not to say it. Homophobia is just like racism; it's hating somebody because they are a member of a group [this is my paraphrasing of what she said].

Dion: People choose to be gay. It's not normal.

Shahbib: $\quad$ It's a disease - it is not natural. My religion says to punish gays - there have to be 2 or 3 witnesses, then you can kill them if you find them together twice.

Neela: $\quad$ What about a girl and girl being together? 
[Dion and Shahbib make jokes, laugh about this. Then, only after his initial response is clearly seen, does Shahbib say "no, no, that's wrong too." Ms. Sarrow is struggling to get them to listen to each other, especially Dion and Shahbib who say incendiary things and then do not listen to what anyone has to say in response.]

Janus: $\quad$ Why do gays have to show off that they're gay?

[Some mention of Gay Pride and flag waving that I can not hear clearly. Viviana is now actively challenging them.]

Shahbib: $\quad$ Every book, religious, that is, says it's wrong. I don't hate them; I hate what they are doing.

[Ms. Sarrow introduces the eraser as "conch" or "talking stick" so they take turns when they speak.]

Craig: $\quad$ Let's think about it democratically. Just like during Black History Month we respected that and learned about that.

JP: $\quad$ Being gay is the result of having too much female hormone. What if somebody with Turret's Syndrome swore at you, would you punch them out?

Perry: $\quad$ No gay person has ever robbed me, punched me, beat me up.

[Someone says...]: You don't go out much.

Perry: $\quad$ Has a gay person ever beat you up?

Natalie If kids see homosexuality on television, like two men with a baby or something, that would be really bad for them. But I say just be what you want to be, if you are homosexual, just be that way.

Santos: $\quad$ I have no problem with gay people. I agree with Natalie, though, I do have a problem with 2 gay people raising a kid. It might make them be gay when they don't want to.

Ms Sarrow: Kids are exposed to many things, as I am sure many of you in this classroom are aware, but that does not mean that they will grow up to become what they see. As long as parents love their child, it is a very great gift, no matter who the parents are. But this idea that children will become what they are exposed to is just baloney. If that were the case, gay people wouldn't become gay, because they are always being exposed to heterosexual culture.

Shahbib: $\quad$ Is God not true then? 
Lenna: $\quad$ Pre-marital sex is a sin too and you have pre-marital sex.

Shahbib: $\quad$ Yeah, but that is not as bad as homosexuality. Being gay is much worse.

Rosaria: $\quad$ I think if a gay couple raises a child it might mess up that child since it will be difficult for them to go to school and see how different they are. Guy and guy and girl and girl is weird.

KG: $\quad$ Raise your hand if you have ever heard of divorced parents. [Lots of hands in the air]

Ms. Sarrow: There are all kinds of families - not just one type of family that is right.

Dom: $\quad$ You say that it is tough for children who have gay parents, but think about children who have bi-racial parents. It is just as tough for them because some people think that is wrong, so are you saying we shouldn't have biracial couples?

Shahbib: $\quad$ But it's not the same thing, it is not natural, it's not right.

Ms. Sarrow: Shahbib, that is what the KKK says about people of different races being married.

Shahbib: $\quad$ So if I have sex with a dog in the privacy of my own home, is that right? Since I am not doing it in public, you can't criticize me can you?

Phil: $\quad$ First of all, the dog cannot give its consent to having sex with you, so if you are equating homosexual sex with rape, you are wrong. Secondly, you mentioned that every religious book on Earth says that it is wrong to be homosexual. But if you check, you will find that every religious book also says that it is wrong to judge another person. We are taught to respect and love each other; otherwise we get hate and hate leads to killing.

\section{[I cannot recollect the rest of discussion between us and I wasn't taking notes of it at the time.]}

Ms. Sarrow: Shahbib, we have talked about this before. I understand how practicing your religion can make you feel vulnerable. There are many times where I feel vulnerable practicing my religion because people might want to kill me for my beliefs.

Shahbib: $\quad$ What if you were in a religious state and they said it was wrong to be gay. Would you criticize that? 
Ms. Sarrow: It would depend on whether I was of that religion or not. But, yes, many people criticize their religion. I have many criticisms of my religion but I still consider myself a part of it.

Craig: $\quad$ What's funny to me is that America is a male-dominated world. You never see anything about lesbians though. Guys are scared of gays because they are worried that they might become gay. [This prompts much laughter and cross-talk.]

Janus: $\quad$ I'm okay with my sexuality. I know that I think she's hot [indicating Neela]. I work with guys who are gay. When I first started working with them, I didn't like them. But then when I got to know them and I didn't know they were gay, I liked them. Then what am I supposed to do when I find out they are gay, turn my back on them?

Santos: $\quad$ Gay sex is wrong because it doesn't create life.

Ms. Sarrow: Plenty of heterosexuals have sex without having children, they do it because it feels good. By that criterion, you would be discrediting heterosexual relationships as well.

Brent: $\quad$ I'm no religion, so this may be easier for me. It's all lies - I follow my own rules. Being gay is not for me, but what's the difference between me liking women and other men liking men? Do whatever makes you happy? Think about witch hunting - how many innocent people lost their lives? And all they were doing was using herbs as medicine, and that's okay now. Religion is just used as something to hide behind.

\section{[I missed some stuff here, I think]}

Janus: $\quad$ Dion, you are not okay with yourself.

Dion: $\quad$ Why do you say that?

Janus: $\quad$ When you find out a friend of yours is gay, you're going to punch him out? Then he is not really your friend; you don't really like him for who he is.

Neela: $\quad$ You can't judge gay people - they are human.

Rosaria: How can you be so hateful when you don't even know a thing about it?

Dion: $\quad$ When you learn something as a kid you will not forget it for the rest of your life. 
Craig: $\quad$ Think of humans as animals, because we are all animals. Think about dogs having sex, they enjoy it don't they? And we all know that if you go to the zoo you will see monkeys masturbating.

KG Craig has brought up a really good point. In high schools we never talk about sex as pleasurable, so we all hypocritically pretend that that's not why we like it.

Craig: $\quad$ Let me ask you this: where's the male G-spot?

Neela: $\quad$ I was taught to reject gays - everybody, my parents, my friends, my religion, taught me to hate gays, but I don't. You have to realize that if you don't accept them it is because you are close-minded.

Shahbib: [after some comments I couldn't record quickly enough] I agree, but in this case it is Okay to be close-minded.

KG: $\quad$ That's just what Hitler said about the Jews. "I'm a Christian but in this case it is okay to kill."

Dion: $\quad$ Yeah well what does that matter? Hitler's dead.

Phil: $\quad H a h !$ He's alive and well.

Janus: $\quad$ Where, I don't see him?

Paula: $\quad$ In people's minds.

Natalie: If you were gay, you wouldn't think it was wrong. I have gay friends; that doesn't make me gay.

Janus: $\quad$ You say being gay is wrong, but so is pre-marital sex.

Shahbib: $\quad$ I agree. But being gay is worse.

\section{[Big reaction, lots of cross talk and angry words. Accusatory.]}

KG: $\quad$ It would help not to attack people; attack their ideas if you must, but let's avoid attacking people directly.

Rosaria: $\quad$ People are scared and defensive. They're scared of what they will find out.

Shahbib: $\quad$ I have read a little bit of the bible, but I don't know everything it says in there. But in the Q'ran - I am not going to bring it in because I don't care what you think- it says that if you meet someone who's gay you should try to change them. And if that doesn't work, and you have 2 or 3 witnesses 
who see two people actually having sex you can punish them. And you can even kill them - and I have no problem with that.

Craig: $\quad$ If extra-terrestrials came to Earth what would you think?

Vivianna: They're trying to take over the Earth?

Craig: $\quad$ Right, you jump to that conclusion because people don't know how to handle the unexpected.

Santos: $\quad$ Shahbib, how does it make you feel when people like you are targeted as terrorists?

Shahbib: $\quad$ I don't like it, but I also don't mind it. It depends. There are 300,000 Muslims in Toronto. When a man who was going to one of the mosques was found to be gay, he was thrown out of every mosque. Every single Muslim agreed that he should be thrown out of the Nation of Islam.

[I think around here is where I spoke about the fact that just because there are a lot of Muslims who think this way doesn't mean that it is right. If there were a community of gays who didn't accept a heterosexual, that would be wrong too. You should think about whether you agree with what your religion is teaching you. I want to read the Q'ran to understand what it says, and I would hope that you would try to understand others. We need to communicate with and learn from each other. I said something like that.]

Rosaria: $\quad$ What if a group said we should throw heterosexuals into the sea? [She was picking up Dion saying that gays should be thrown in the sea.]

Dion: $\quad$ They couldn't-I'd like to see them try. We are too strong. Let them try.

Natalie: $\quad$ I'm going to ask a question: if gays ganged up on heterosexuals, how would you feel?

Dion and Shahbib: $\quad$ Don't worry about it. It's not going to happen.

Perry: $\quad$ People following religion, I have noticed that they only follow the rules they want, and forget about the rest.

Neela: $\quad$ Let's just end this conversation; we're not going to change their minds. This isn't new to me, I have talked to them before about this, and they aren't going to change their minds. 
Ms. Sarrow: I don't think we should think about this as only educating two people. We are all learning by being involved in this discussion. It's an important discussion to have, along with talking about racism and sexism.

Dion: $\quad$ Why does she always bring racism into it?

Ms. Sarrow: This is a conversation about divisions within societies. And I know it is hard to sit here and listen to it.

Perry: I Ion't hold it against them for how they feel. I feel the way I do, and they feel the way they do. But it is better to talk than to fight.

Rosaria: $\quad Y o u$ can feel what you want, but it has to be grounded in reasons. You can't just say what you think without having some reason for it.

Shahbib: $\quad$ Miss, what does the Torah say about gays?

Ms. Sarrow: I don't know exactly, but I do know that it says that if a man masturbates he should be stoned. I'm Reformed, I practice, but I am not observant. I have lots of problems with the teachings of my religion.

KG: $\quad$ I have taught in high school for 10 years, and in University, and have observed a lot of classes and I have to say that this is one of the most engaged debates I have ever witnessed. You are lucky to have Ms. Sarrow as a teacher. Other teachers might have shut this discussion down in a minute. Even though it is difficult, it is also important to expose these conflicting views if we want to move ahead and be responsible for a more just society.

Ms. Sarrow: I'm going to cry-- I'm sorry, I feel very emotional. I love this class a lot ("We love you, Miss!" they respond). I want you to know that I respect what people say and that doesn't change what I think of you. We always have very intelligent discussions in here. I hope we can be more open in the future to having our views challenged if they exclude or marginalize others.

Perry: $\quad$ American History $X$ is a great movie about just this stuff.

Ms. S: It's fitting we have this discussion on December $6^{\text {th }}$, does anybody know why?

Shahbib: $\quad$ Canada's first massacre. Fourteen women in Montreal.

Ms. S: $\quad$ Right. And why did he kill them?

Neela: $\quad$ [I think it was Neela] Just for being women. 
Ms. S: $\quad$ Right.

Fade to Black

BEAT THREE

Kathleen: (upstage right) Beat Three: "The Pass"

Phil moves into a spot downstage left and reveals a sign, which reads:

\section{"Disclosing a little of the undisclosed margins" \\ Gayatri Spivak, Explanation and Culture: Marginalia, 1990.}

Arden (downstage right): Today was incredibly hard. I could barely see or hear what was going on in the class, for all the visions and memories and emotions that were being triggered for me, for the weight of history - my own, my family's, my friends, that of the youth with whom I've worked, the world's - bearing down on me.

And I felt compromised. I had passed as straight. I have no doubt about that, not after today. I kept looking for the little glances, the subtle body language, kept listening for the murmured comments or stifled giggles, yet there were none of those - I had successfully " "passed." Part of me thinks that's great - my identity hasn't compromised the research dynamic - and yet a huge part of me rails against that. Does Phil wonder about whether being a man compromises our research? Do Dom and Kathleen worry about what being women means for what they will hear or witness? Does Dom worry her blackness will change that? Do Phil, Kathleen and I worry about the many ways our whiteness affects, or indeed limits, what we will witness, or even be able to see or hear? And because I now feel like I know them, I feel like I can safely say yes - we do, they do, I do, we all do worry about that. But I do not believe that constant questioning, that agonizing self-assessing, is common for most researchers.

I found it incredibly challenging to be present today. I desperately wanted to leave, to yell, to shout, to throw things, to give some voice, some outward manifestation of the rage and pain seething, bubbling, boiling inside me.

And to sit in a room on December 6, and listen calmly to people say a group of people should be punished or killed - who even cares what group that was - was abhorrent! And yet of course I care, because this was not just any group - this was not the distance of East Timor, or Chechniya, or Somalia - this was about me! I was sitting in that room, calmly (at least outwardly so) listening to teenagers declaim my status as sick, diseased, sinner, having too many female hormones - as pervert, mentally ill, as deserving judgement, punishment, torture, banishment, death - and as having chosen all this!

Yet I know that there are those with whom I feel I share a community, who I look upon as siblings in the great gay struggle, who know their queer orientation to be a choice, while at the same time I feel mine was in-born. I felt different since kindergarten, and remember thinking that having the boys run after the girls in kissing tag felt wrong, 
even when I was only 6 years old. Yet even then I had already learned enough to stay silent.

And I know one other thing - I would choose it, I would choose to be gay. I wouldn't have chosen it back then, when I still felt embraced by parents, culture, church, God, and felt blissfully unaware of the extreme conditional nature of that embrace. But knowing what I know now - knowing that being gay made me grapple with all these complex questions of oppression, power, difference, gender, sexuality, compassion, justice - knowing that struggle made me the caring, strong, proud, AWARE person that I am today - knowing all that, I would choose it again and again, and a thousand times over.

But I could not declaim that today. I could not even meet the eyes of Dom or Phil or Kathleen, for all that their presence made me feel stronger and incredibly supported, because I felt sure that if I did meet their eyes, the careful, professional façade would crumble, and I would indeed cry, yell, and externalize the powerful sea of emotions crashing against the shore of my heart.

I looked at the floor, and I looked at my notebook, and sometimes I could contain it all well enough that I could even look at people talking - even Shahbib, even Dion.

I saw my grandparents and my father being led to the gray living death of work camps and concentration camps. I saw the bruised, swollen, bloody, unrecognizable face of a gay bashing victim - a friend - a morass of purple and crimson and pain-filled pinks, floating on the antiseptic white of a bed in I.C.U. I saw the eight inch blade that I carried with me through much of high school, snakes engraved on sharpened steel - I knew it was suspension, even expulsion to be caught with it - but I feared for my life, and what's expulsion compared to that, and who'd ever think that a sissy nerd like me would carry a knife?

I heard the voices of a year's worth of nights spent answering the phones at the Lesbian Gay Bisexual Youth Line, the tales of two years spent facilitating the Newcomers groups at Lesbian Gay Bisexual Youth of Toronto at the 519 community centre, the litany of pain and pride and hope and fear that filled four years worth of Trent University Queer Collective and Peterborough Rainbow Youth groups. I heard the stories of rape, and name-calling, and bashing, and emotional abuse, and teachers standing by, or even joining in. These voices echoed, yelling, whispering, pleading, crying - wrapping themselves like crimson silk around the sharp sounds of Dion saying he'd show any guy that tried to come on to him a five inch blade.

My heart bled today, from a thousand old wounds, from scabs I thought long healed. My heart bled today, because I knew there had to be some queer kids in that class today, and if I, with my years of strength and pride and support and friends, if I could barely stand it - then how could they?

And I know the answer is simple - survival. A betraying wince, an unwelcome twitch or shiver, a moment of unguarded emotion - that's all it would take to be a marked target, to be a marked victim. I was never as good an actor as I wanted to be - for I was marked - and I still have the physical and emotional scars to show for it.

Today was a wealth of research data - and yet I probably missed much of it. For the brutal truth is that I could not get it together in there today, couldn't "keep it together." Everything I normally consider to be gifts, as a person, as a teacher - all those felt like weaknesses today - my empathy, my deep commitment to social justice, my 
ability to clearly visualize or hear multiple meanings, images, sounds connected to whatever's being focused on, my expressiveness, my openness - every single one of those felt like an open wound, drinking in the acid and bile of hatred and prejudice that rained down in the discussion today.

I was silent today. I didn't say a single word, from the moment the discussion began, until after Kathleen locked the door and brought us together for a moment I didn't think I could handle, but oh so desperately needed. Not one word. That silence weighs heavily on me still. I know I did what I thought I needed to, what I thought would let me "keep it together," or at least appear to. And yet I ache, for that thundering silence reverberates in the depths of my wounded soul. And I feel like I must step away from these research shoes; I strongly doubt that I can fill them anymore, for as strong as I feel, I do not think I have the strength.

With all my years of teaching and facilitating, of doing speaks and performances around social justice, human rights, violence against women, being gay, homophobia after setting up the Lesbian Gay Bisexual Youth Line, after years with Lesbian Gay Bisexual Youth of Toronto, the Trent Queer Collective, the Peterborough Rainbow Youth Network, after Act For (a touring human rights theatre production), and starting the Student Human Rights Advocacy program at Trent University, and Men Against Violence Against Women, and the Trent Fashion Show (a celebration of all kinds of beauty, and a fundraiser for Crossroads' women's shelters), and being the LGBT Students' Rep on the Ontario board of the Canadian Federation of Students - after all that... I still could not speak today - and indeed felt that it would fall on deaf ears.

I am amazed by some of the risks people took today - Vivianna, Neela, Craig even Janus. That gives me some hope. But Ms. Sarrow is leaving teaching. I don't know if I can ever go back there. And people like us last but a few years before burning out, or flipping into auto-pilot. The few that last, for all our deconstruction of the hero narrative, are heroic. The few who care so passionately, who empathize and agonize - and somehow do that year in and year out - they truly are heroic. I just don't think I can be one of them...

Blackout.

\section{BEAT FOUR}

Kathleen: (upstage centre) Beat Four: "The Poetry of Urban: An Interview"

(The empty classroom. Lights up downstage centre)

The Players

Phil: White, American-born graduate student research assistant, 37 years old.

Dion: Black, Jamaican-born grade 11 high school student, 19 years old.

Phil: $\quad$ Why did you take Drama? 
Dion: $\quad$ Because I wanted to see, I heard it's fun and I prove it for myself right now that it's fun.

Phil: $\quad$ Okay. Um, what might prevent you from being actively involved? So on those days where you're not, what happens that makes you think "ahh, I don't want to do this"?

Dion: $\quad U m$, sometimes the discussion. Depends what the discussion's about. Like for instance, I don't like the discussion about um for instance gay, I don't like to hear about them, you know? If they're going to discuss that, I want to be out of the class. That's just me, I can't change.

Phil: So yeah, we had that big talk about uh homophobia, homosexuality, and you were a big participant in that discussion. Uh, but then you did leave.

Dion: $\quad$ Yeah I did leave.

Phil: $\quad$ Um, so in your opinion, does it, is there any good reason to have that kind of talk? Do you think there can be anything positive about that?

Dion: $\quad$ Sir, that's just the way I grew up still like, you know. Back in my country, that's how I see they react and it's hard to change cuz you know like Friday I turned 19 and grew like that when I was 1 and I start understanding you know what I'm saying, so it's hard to like you know, I'm just going to stay with that decision, you know what I'm saying?

Phil: $\quad$ So, you don't think that will ever change about you?

Dion: $\quad$ Sir, I don't think so, straight.

Phil: $\quad$ And do you think anybody's opinion would be changed in that room by having a talk like that?

Dion: $\quad$ Sir, I guess like most people in there they want to say something but because um some people opinion are stronger they just hold it down, you know what I'm saying? Cuz they don't want to be embarrassed, but I'm not scared, you know, I say what I feel like. What's true, or what's right, you know what I'm saying?

Phil: $\quad$ Well, I guess. I mean what I'm curious about is, I mean, you just said about Drama that one of the things is that you have to drop yourself and try to become another person, another character, um and that's something that Drama really focusses on, but then you are saying nothing will change your opinion. So I'm wondering how do you change yourself to be in character and then say "oh yeah, but this I know will never change about me"? 
Dion: Sir, but um, I never get like that type of character to play in the class, like a gay role. Cuz I won't play, that's the only thing I won't play, you know what I'm saying? I'll be anything else, but I'm just not going to play a gay role.

Phil: $\quad$ Is that because you would be embarrassed to do it?

Dion: $\quad H u h$ ? Sir, no. It's just that the way that that just the way that I feel; I don't want to play, because if you play you're just being it at the same time.

Phil: $\quad$ Oh, oh, so part of you would have to be gay to play a gay?

Dion: $\quad$ No, no, it's not like that Sir. Don't get me wrong. You could play, but it just might, it might, I just don't feel like to play you know what I'm saying? You could play it and you're not gay, that's straight, but you know just for the marks, you play it, but I just don't feel comfortable playing it though.

Phil: Uh, but if you know that it's just pretend. Like I'm thinking if there's a role where you have to be a murderer, you know a serial killer, or something, I wouldn't necessarily want to be a serial killer, that's not something I would want to be, but as part of the play I would say "okay, well I am going to give it a try" and I would try to make it seem as real as possible, and I would know that everybody in the room wouldn't think that I was a serial killer, right?

Dion: $\quad$ Sir, I know what you saying, but it's just that I don't know Sir, I just can't play them role, I just don't feel comfortable playing that gay role.

Phil: $\quad$ I guess I'm just asking what makes you uncomfortable about it. Is it that you think people would think you're gay? Or is it something else.

Dion: Yes sir, it's something else. Basically, I don't care what people think, you know? That's just plant inside of me Sir, I can't get rid of it, you know what I'm saying? Like, it's just in me you know, how I see people back home deal with the situation, the whole situation, gay situation, just in me, Sir just in me it's like it's plant like, you know something that grew up inside of me like from a little plant you know what I'm saying? Into a big tree, you know what I'm saying?

Slow fade to Black.

The End. 


\section{Epilogue}

The epilogue of this paper will begin to deconstruct the ethnographic scenes, the four BEATS $^{4}$, of the above short play. The setting is a rather "typical" urban, public school where a culture of discrimination based on sexuality is "fair game"; where symbolic and physical violence against queer youth is viewed by most youth as a crime unequal to other forms of discrimination based on gender, race, or class, for instance. On the hierarchy of oppressions, homophobia barely makes the list. I will argue that the social designation of gay/lesbian/bisexual youth, their "invisible minority" status is, at least in part, enacted/effaced through a set of moral regulations in the classroom. Notions of masculinity and some theorizations of "the pass" will also be considered. "The pass," a term once specific to African American experience (Nowlin, 1999) is now in vogue with queer theorists. "The pass," as described with respect to a critical episode in one of our school sites, should be understood as the social dynamics experienced by gays/lesbians when others presume them to be heterosexual by openly ridiculing homosexuals or shaming those suspected of being queer into silence.

The study I am currently leading, titled Drama Education, Youth, and Social Cohesion: (re)constructing identities in urban contexts, examines the experiences of youth in urban drama classrooms, in order to develop a theoretical and empirically grounded account of the dynamic social forces of inclusion and exclusion experienced by adolescents within their unique contexts of urban North American schooling. The

\footnotetext{
${ }^{4}$ Beats 1 and 3 are drawn from the reflective researcher writing that followed the incident presented in Beat 2. As four researchers, we all wrote and shared our reflections following our time in the classroom. The question I posed to prompt our writing was: In what ways did you make yourself present and absent during the discussion? Beats 1 and 3 represent Arden's response to this question. Beat 2 is the classroom episode that sits at the centre of this discussion about homophobia in the high school classroom. It represents the actual dialogue that occurred that day and is a compilation of the copious notes of four researchers. Beat 4 is the transcript of one interview with one student participant.
} 
ethnography of four urban sites (two in Toronto, Canada; two in New York City, USA) is concerned with investigating the extent to which drama education in classrooms illuminates the intersections of youth's personal/cultural lives with their school lives in the formation of their social identity. The performative and contingent nature of identity will be especially important to consider as I attempt to unpack the account of a classroom episode from one of our Toronto sites (Beat 2). In this analysis, I will pay particular attention to notions of masculinity and identity construction.

\section{"The Pass"}

Although all four researchers had important post-classroom reflections, the ethnographic play has centred on the experience of Arden, an openly-gay, White male researcher, because of my interest in pursuing a particular notion of the "absent-presence", , in light of a discussion of (masculine) identity construction and performance in the classroom. Kimmel (1994) states: “Our fears are the sources of silences, and men's silence is what keeps the system running" (p. 131). It is obvious that Arden did not want his silence mistaken for approval of the things that were being openly expressed. Wittig (1992) contends that we are oppressed by heterosexual discourses because they prevent us from speaking unless we speak in their terms; in fact, that their most ferocious action is "the unrelenting tyranny that they exert upon our physical and mental selves" (p. 25).

Methodologically, we attempted to discuss how each of us (researchers) had "passed" that day, we were encouraged by Kincheloe and McLaren's (1994) notion of "reflective humility," the praxis of the critical and the radical uncertainty of the postmodern. In addition, there was something about the act of witnessing in that 
classroom that needed to be processed. I have since come to realize that this kind of personal theorizing, or symbolic reflexive dialogue between researcher and researched and among researchers themselves, speaks to Spivak's (1990, p. 377) idea of "disclosing a little of the undisclosed margins" in our academic writing in an attempt to deconstruct the duality of public and private.

\section{Masculinity Goes to School: ultimate identity or ultimate fiction?}

Kimmel's (1994) definition of masculinity, its social construction, will be considered here as we deconstruct the ways in which homophobic attitudes get rationalized, normalized, and even justified in many school contexts. Kimmel writes:

...I view masculinity as a constantly changing collection of meanings that we construct through our relationship with ourselves, with each other, and with our world. Manhood is neither static nor timeless; it is historical. Manhood is not the manifestation of an inner essence; it is socially constructed. Manhood does not bubble up to consciousness from our biological makeup; it is created in culture. Manhood means different things at different times to different people. We come to know what it means to be a man in our culture by setting our definitions in opposition to a set of "others"-racial minorities, sexual minorities, and, above all, women. (p. 120)

For Kimmel, the development of masculinity is a "homosocial" experience. "Man" is self-made and based on homosocial competition. Masculinity must be proved and proved

\footnotetext{
${ }^{5}$ Gratitude to Deborah Britzman for coining such a revealing term.
} 
again, for women, for other men, and for individual men themselves. Kimmel's hegemonic masculinity within the dominant culture is the masculinity that defines white, middle class, early middle-aged, heterosexual men. Citing Brannon (1976), Kimmel suggests that this dominant masculinity relentlessly repudiates the feminine. He argues, "whatever the variations by race, class, ethnicity, or sexual orientation, being a man means "not being like women." "This notion of the anti-femininity" he offers, "lies at the heart of contemporary and historical conceptions of manhood, so that masculinity is defined more by what one is not rather than who one is" (p.126).

What is particularly key to Kimmel's argument is that the performance of masculinity is basically for other men. In insisting that masculinity is a homosocial enactment (whose overriding emotion is fear), he argues that men are constantly under the scrutiny of other men. "We test ourselves, perform heroic feats, take enormous risks, all because we want other men to grant us our manhood" (p. 129). Dion's verbal tick in Beat 4, "Sir, you know what I mean?" may be more than interview nerves at work. He is possibly also looking to Phil for a confirmation of his own manhood. Kimmel argues that in adolescence, boys learn that peers are a kind of gender police. The ultimate paradox, of course, is that men who may appear to have "the power" ultimately feel powerless because his reigning definition of masculinity suggests it is "a defensive effort to prevent being emasculated" (p. 135).

In his reasoning, Kimmel proposes further that homophobia is a cause of sexism, heterosexism, and racism. In Beat 4, Dion and Phil are referring to the classroom discussion (Beat 2) that followed a performance brought into the school to deal with the issue of HIV/AIDS. Interestingly, in this issues-based play performed by a school touring 
theatre company, there were no gay characters. The play followed the stories of two straight couples who were dealing with issues of sexual relations and HIV transmission. There was no "gay" storyline. But the day following the classroom presentation, one student wondered aloud whether one of the male actors was actually gay. The 76-minute, volatile, and at times violent, debate (presented as Beat 2) that ensued that day had an enormous impact on our research team, the students and their teacher.

As a classroom discussion, this scene provides us with astonishing insight into the passion and fear with which young people react to issues concerning sexuality. A critical definition of homophobia, according to Pronger (1999), is the fear of the erotic violation of gender; the fear of the exposure of the tenuousness of gender; the fear of the disruption of power relations. The students' insistence that gay men have too many female hormones or that two men with a child is profoundly "unnatural" would suggest that an erotic violation of gender, and not simply an irrational fear of homosexuality, is at the centre of the students' expression of homophobia. It also confirms their belief in a dichotomous sex-gender system, that there are only two sexes and that gay men (and lesbians) can only be explained on a female-male continuum. At face value, with few dissenting voices, the discussion appears to claim "open season" on homosexuality. Even those who "defend" homosexuality often qualify these defenses with "heteroprivilegist" (Crowhurst, 2002) notions. The students are, at some moments, articulating quite sophisticated understanding. Those on both sides of the issue argue with conviction. Some students passionately contradict themselves during the course of the loaded discussion.

In this very racially and ethnically diverse group, there were many strong opinions put forward. While there is much to examine in the scene, I would like to focus 
particularly on three students, two racially minoritized boys and one White boy. Kimmel illustrates that, historically, the masculinity of non-white men has been suspect either because they were cast as less than manly (Asian men) or "hypermasculine" and therefore savage (Black men). In this episode, the two most persistently condemning voices were Shahbib and Dion. Shahbib continually grounded his "opinions" in his religion, but not religion as practice, rather religion as ideology. Claiming his Muslim identity, he used his religion to support what were, in many instances, openly hateful comments. This did not go unchallenged by several students (and researchers and teacher), including other Muslim students. Fuss (1989) talks about the ability of claims of "personal experience" to shut down discussion in classrooms. While such experiential knowledge must clearly be valued, in this case, it also served to reify the Muslim faith in ways that did not invite other (Muslim) students into the conversation. In this case, Shahbib believed he was standing in for all Muslims, as his examples would suggest. Dion, on the other hand, a Christian, Jamaican boy refused to have homophobia compared, in any way to racism, which his teacher did on a number of occasions. He was also demonstrably uncomfortable with Dominique's assertion that mixed-race marriages have historically experienced the same forms of discrimination. For Dion, it was unthinkable that discrimination on the basis of race was at all comparable to something he sees as inherently wrong; race is "natural," homosexuality is not. It is also important to note here that race is construed as a stigma attached to races other than White.

These two young men did not garner much support from others in the class, particularly other White boys. It would seem that a "homophobic masculinity," a masculinity constructed through an extreme "othering" and demonizing of gay men 
would not gain universal approval here. The sexual regulation of this classroom slowly moved toward a "live and let live" ideology but not without conditions. Being gay is okay but raising children in such environments is not. It was, ultimately, a qualified acceptance according to most in the room. The issue, of course, of double standards, for women and men is a familiar one. Lesbians are tolerable because, at least in a sexist culture, lesbian sex can be imagined as a heterosexual male commodity, hence Kimmel's assertion: "Homophobia and sexism go hand in hand" (p. 133). In this case, even the most (hetero)sexually fundamentalist students could not remain self-consistent, instead favoring a heteropatriarchal sexism, even if it is permissive of a certain kind of (female) homosexuality. It was indeed revealing that several of the female students in the class hovered around the classroom door after the bell, complaining to one another that they hadn't been given an opportunity to express their views. Two of the most vocal girls in this conversation were Muslim. Living their intersectionality, their gendered-racist oppression, they were obviously disturbed by their (double?)"silencing” on both issues of gender and faith.

Janus, a large White boy and captain of the football team, is the one to blatantly challenge Dion. His challenge, however, confirms a masculinity that defines itself through sexism: "I'm okay with my sexuality. I know that I think she's hot" (indicating Neela). Ever prepared to demonstrate sexual interest in a woman, Janus demonstrates the "right" masculinity, where the traditional form of (hetero)social order appears as "normal." In the end, Janus reclaims the cultural capital with a - seemingly tolerant in one instance, oppressive in the next - masculinity that both objectifies women and repositions "real" men as (hetero)sexually vigilant. The cultural capital of this White boy 
also further allows him to become the spokesman for (liberal) western civility. A psychoanalytic reading of this intervention, however, would suggest that he is "identifying with the agressor"- in this instance, Dion- as a way to expel his own guilt (see Britzman, in McCarthy, Crichlow, Dimitriadis and Dobly, 2005). To add to this complexity, we- researchers, teachers, "tolerant" students- wanted such oppositional voices to surface, those with more generous readings of minority sexualities. Through our own and others' investments, we became acutely aware of the performative nature of racialized, religious, gendered, and sexual affiliations in these charged classroom moments.

Aware of the politics of representations of Islam in the West, as researchers we became particularly conscious of the dangers of essentialism in the classroom, how pervasive and consequential it is when students of colour are positioned in empirical research in ways that "reveal" them as standing in for their race/culture/religion. Our classroom episodes provide examples of how sexuality, religion, and other identity categories and affiliations are being positioned against one another as a matter of course in high schools. This empirical work, recounted as a set of scenes/beats in this paper, makes it challenging to conceptualize difference in abstract ways, as bodies are there and always marked. But the scenes do demand that we carefully rethink the linkages we draw between and among gender, sexuality, culture, experience, and race. Rizvi (2005) describes the "intense stuggle within Islam between those who view Islam in terms of an "authenticity" and those who regard syncreticity as essential to the development of a modern view of an Islam committed to democracy and justice" (p. 176). In our view, the world of multiplicity destabilized the established school curriculum on this day. But what 
do such accounts tell us about how school knowledge and classroom pedagogy is organized?

\section{Where do we go from here?}

Two weeks after the classroom discussion, Dion was expelled from Middleview Tech for brandishing a metal pipe and threatening another student at the school. Paul Willis (2005) says youth are the "unconscious foot soldiers in the long front of modernity", those most disenfranchised by the reorganization of capital, what he characterizes as the "third wave" of modernization, wherein working class children- particularly male youth- have been displaced by deindustrialization and the changing information and service-based nature of the economy.

If we wish for our educational policies, and especially those relating to issues of equity and diversity, to hearken a new political and educational era, we must find ways to address the interlocking forms of oppression based on social categories that attach to young people's bodies, at times like led weights around their necks. Difficult conversations are required to challenge culturally inscribed notions of identity and particularly the sexual regulation of youth identities. Unchecked assumptions about the gay Other not among us, but somewhere "out there" will continue to silence youth in classrooms. We might begin to interrupt these deafening silences by making visible the "invisible" sexual minority presence, not simply in the form of individuals, but as a named social category in unremitting interaction with other more visible identity markers. Sexual identity and desire need their place in high school conversations; conversations that engage the radical uncertainty of the postmodern subject in the very real material 
realities of sexist, racist, and homophobic classrooms. It is important, for instance, that Shahbib and Dion not be vilified for speaking attitudes held by many young people of all racial backgrounds. Rather than essentialized identities, "standing in" for their gender/race/religion/culture they, too, are participants in a negotiated (classroom) culture based in mysogynist, heterosexist and racist precepts thereby (re)producing relations of power that privilege certain masculinities over others and generally disadvantage racially minoritized people as a matter of course. Only these kinds of difficult conversations can produce the necessary antecedent to positive experiences of "coming out."

What young people are expected to "come out" into- classroom cultures riddled with sexist, homophobic, racist "norms"- will require that "sex education" as the traditional discourse in school move beyond pathologizing discourses of "sexual orientation" and afford same-sex and opposite-sex attracted young people the freedom to articulate the fears, misconceptions, and desires they may have. In creative urban drama classrooms, we must take up questions of race, class, sexuality, disability, ethnicity, accent discrimination, and sexism as though they mattered to one another. To examine, in our research, the ways in which sexuality and other identity markers are socially constructed and performed, how the moral, gendered and discoursed cultures created in classrooms reinscribe historical inequities is the most pressing job, I would now argue, of classroom-based research.

Finally, why present this work as ethnographic scenes? To expressly create ethnographic scenes from classroom-based research, to use theatre as metaphor in order to make explicit the performances of identity in these charged environments, is to put the "once removed" frame around these "data" but also to keep alive the immediacy of the 
discourse, and the tensions and theatrical turns of everyday life. This attempt to use theatre- rather than present these research stories in more traditional qualitative narrative or reportage form- is to draw from theatre's potency, its economy of expression, and its embodied character in order to serve the creativity, the performativity, and the reflective engagement that is at the centre of critical ethnographic research.

\section{Implications for Researchers and Educators in LGBTQ Issues}

It might be argued that the classroom discussion represented in Beat Two has crossed a line. Some might say that the discussion allowed hateful attitudes to render unsafe the classroom environment. We know, unequivocally, from Beats One and Three that Arden struggled terribly with his "participation" in this classroom. How many others, without his confidence and experience, were distressed by the discussion? I cannot easily answer this question but what I do know from years in high schools is that the homophobia that is often forced underground by liberal ideologies, is at least as dangerous and damaging. The (symbolic) violence experienced by lgbtq youth in regular classrooms is well documented. While exposing the attitudes that permit such violence may not eradicate it, I firmly believe that such attempts at difficult conversations hold out, as a minimum, the possibility for education. Participants in such discussions must be held to account for what they believe and articulate.

Teachers, including Ms. Sarrow herself, revisit their teaching actions regularly and on this particular day, Ms. Sarrow was attempting to balance her desire for better understanding for those students most demonstrative about their homophobia, while working hard to reclaim her "just" and "safe" classroom environment for all students. If 
confronted by such a discussion again, she might make different choices. But what I most admired about Ms. Sarrow's facilitation, was her efforts to keep the doors to social justice open by pointing to the ways in which our (school) communities have been historically and continue to be cultivated through processes of exclusion and injustice. Her "exercising of authority" (Rizvi 2005) was performed in ways that were ever conscious of the greater subjection to discrimination that is the experience of some of her students. She is well aware of how some students, particular minority students, are currently constituted and how they might be reconstituted in public pedagogies. She never lost sight of her own position of relative power in the discussion and, therefore, her responsibility to her students. She accomplished her difficult work on this day by helping the youth in her charge to be heard and to hear things that invited them think to through the complexities of their own sexual, gendered, racialized, and religious identities and affiliations. And she remained steadfastly with them, especially in the moments where their ideas seemed both unsophisticated and uncomplex; she also made herself, rather vulnerably at times, an "equal player" in the discussion.

As I consider the implications of this work, I am left, for better or worse, with a set of questions, drawn from the experiences of this research. With these, I hope to invite researchers to reflect on how our research and teaching experiences in classrooms- and our hopes to better support lgbtq youth in these classrooms- might be strengthened. While the study is interested in the performative aspects of youth's social and artistic identities, it also points intentionally to the performative aspects of the research event itself.

Research as theatre holds exciting possibilities for critical teacher development when it forces us to resist the passive consumption of research while moving "audience" 
closer to the role of "spect-actors", as Boal (1994, in Schutzman and Cohen-Cruz)

conceives it, refering to the activated spectator, with choices and potential involvement. I remain interested in the pedagogical and research possibilities uncovered in "aesthetic spaces" that re-present the potentialities for a dynamic seeing and being seen, for the recognition of the self and the other, and the expressions of desire for change in everyday life (Feldhendler, 1994) and classroom life.

To this end, I offer the following questions in conclusion:

- What are the ethical/political considerations of outside researchers observing and participating in, as well as "performing" the data? Can such performances address concerns about the privileging of certain voices and the marginalizing of others, like lgbtq youth?

- In a climate increasingly inhospitable to open inquiry into gender/sexuality, how can arts-based research be utilized to bring important ideas about how gender/sexuality is lived to a wider audience? What challenges do we face in this regard? What are our responsibilities in reporting this research? In addressing students' preconceptions around such topics as homosexuality, religion, and masculinity, how can we, as researchers, participate/intervene? What are the unique characteristics of performance research that might aid in this effort?

- How do we, in the academic community, hide/reveal ourselves in our research of lgbtq topics?

- What are the possibilities for moving forward, as researchers and/or educators, within such a climate of fear, ignorance, and hate?

- How are we constrained/enabled by our position in education research? 
- How can we ensure that our (performed) research includes historical and structural considerations of our topic, like the gendered nature of schools, for instance?

- What voices are privileged and which silenced in a move toward arts-based research?

- How do we avoid the urge toward resolution and catharsis in (performing) our research?

- What claims can we make to researchers in related fields about the validity of performance as a research modality?

- How does the unfinished-ness of the "final account", therefore, serve/limit us? What is the challenge to dissemination if we take seriously the idea that the research act is unfinished until it meets its intended audience? How do "consumers" of research continue to "produce" or "co-produce" knowledge? How might these performances of research engage a youth audience? A teacher educator audience? The larger scholarly community? 


\section{References}

Adkins, A., \& Gunzenhauser, M. G. (1999). Knowledge construction in critical ethnography. Educational Foundations, 13(1), 61-76.

American Psychiatric Association. (2000). Mental illness: An overview. Retrieved from http://www.psych.org/public_info/overview/cfm

Bagley, C., \& Tremblay, P. (1997). Suicidality problems of gay \& bisexual males: Evidence from a random community survey of 750 men aged 18 to 27 . In C. Bagley \& R. Ramsey (Eds.) Suicidal behaviours in adolescents and adults: Research, taxonomy \& prevention (pp. 169-186). Brookfield, VT: Avebury.

Brannon, R. (1976). The male sex role - and what it's done for us lately. In R. Brannon \& D. David (Eds.), The forty-nine percent majority (pp. 1-40). Reading, MA: Addison-Wesley.

Britzman, D. (2005). A note to "Identification with the Agressor". In. C. McCarthy, W. Chrichlow, G. Dimitriadis, and N. Dolby (Eds.) Race, Identity, and Representation in Education, second edition. (pp. 179-190). New York and London: Routledge.

Canadian Mental Health Association. (2002). Fast facts. Retrieved from http://www.cmha.ca/english/info_centre/info_frmset.htm

Crowhurst, M. (2002). Heteroprivilegism: Three layers of discriminatory practices that target non-heterosexual subjects. $N J, 26(2)$.

Drama Australia. (2003). Drama Australia equity and diversity policies

Feldhendler, D. 1994. Augusto Boal and Jacob L. Moreno: Theatre and Therapy. In Schutzman, M. and J. Cohen-Cruz.(eds.) 1994. Playing Boal: Theatre, Therapy, Activism. Routledge: London and New York. pp. 87-109. 
Excellence for all in public education (2003, November 20). In Speech from the throne: Strengthening the foundation for change (pp. 7-9). Retrieved from http://www.ontla.on.ca/documents/2003_throne_speech_english.pdf

Fuss, D. (1989). Essentialism in the classroom, in Essentially Speaking. New York: Routledge.

Hillier, L., et al. (1999). Whatever happened to duty of care? Same-sex attracted young people's stories of schooling and violence. Melbourne Studies in Education, $40(2)$.

Kimmel, M. S. (1994). Masculinity as homophobia: Fear, shame, and silence in the construction of gender identity. In H. Brod \& M. Kaufman (Eds.), Theorizing masculinities (pp. 119-141). Thousand Oaks, CA: Sage.

Kincheloe, J. L., \& McLaren, P. L. (1994). Rethinking critical theory and qualitative research. In N. Denzin \& Y. Lincoln (Eds.), Handbook of qualitative research (pp. 138-157). Thousand Oaks, CA: Sage.

Lesko, N. (2001). Playing with high school athletic privilege and power. In Act Your Age! A Cultural Construction of Adolescence. (pp. 149-170). New York: RoutledgeFalmer.

Ma, X. (2000). Health outcomes of elementary school students in New Brunswick: The education perspective. Evaluation Review, 24, 435-456.

Nowlin, M. (1999). Beyond identity politics? Canadian Review of American Studies, 29(1), 133-142. 
Ollis, D., et al. (2000). Safety in our schools: Strategies for responding to homophobia. Melbourne: Australian Research Centre in Sex, Health and Society, La Trobe University.

Pronger, B. (1999). Fear and trembling: Homphobia in men's sport. In P.

White \& K. Young (Eds). (pp 182-196). .Sport and Gender in Canada, Oxford University Press.

Don Mills, Ontario 182-196.

Rivers, I. (1997, July). The long-term impact of peer victimization in adolescence upon the well-being of lesbian, gay \& bisexual adults. Paper presented at the 5th European Congress of Psychology, University College, Dublin, Ireland.

Rizvi, F. (2005). Representations of Islam and Education for Justice. In C. McCarthy, W. Chrichlow, G. Dimitriadis, and N. Dolby (Eds.) Race, Identity, and Representation in Education, second edition. (pp. 167-178). New York and London: Routledge.

Sallis, R. (2003). Worthy of our school. Draft document. Melbourne: University of Melbourne.

Schneider, M. (Ed.). (1997). Pride \& prejudice: Working with lesbian, gay and bisexual youth. Toronto: Central Toronto Youth Services.

Shugart, H. A. (2003). Performing ambiguity: The passing of Ellen DeGeneres. Text and Performance Quarterly, 23(1), 30-54.

Spivak, G. C. (1990). Explanation and Culture: Marginalia. In R. Ferguson, M. Gever, T. M. Trihh \& C. West. Out There: Marginalization and Contemporary Cultures. (pp. 377-394). Cambridge, Massachusetts: MIT Press. 
Torsheim, T., \& Wold, B. (2001). School-related stress, school support, and somatic complaints: A general population study. Journal of Adolescent Research, 16, 293303.

Willis, P. (2005). Afterword: Foot soldiers of Modernity: the Dialectics of Cultural Consumption and the $21^{\text {st- }}$ Century School. In C. McCarthy, W. Chrichlow, G. Dimitriadis, and N. Dolby (Eds.) Race, Identity, and Representation in Education, second edition. (pp. 461-479). New York and London: Routledge.

Wittig, M. (1992). The straight mind. In The Straight Mind and Other Essays. (pp. 2133). Boston: Beacon Press. 